\title{
FERTILITY FOLLOWING BILATERAL INTERNAL ILIAC ARTERY LIGATION
}

Sumit H. Paranjpe ${ }^{1}$, Pratima Thamke² ${ }^{2}$ B.G. Boricha ${ }^{3}$

\section{HOW TO CITE THIS ARTICLE:}

Sumit H. Paranjpe, Pratima Thamke, B.G. Boricha. "Fertility Following Bilateral Internal Iliac Artery Ligation". Journal of Evolution of Medical and Dental Sciences 2014; Vol. 3, Issue 04, January 27; Page: 926-929, DOI:10.14260/jemds/2014/1925

ABSTRACT: Objective: To assess a case of infertility and amenorrhea following bilateral internal iliac ligation for post-partum hemorrhage. Review of literature shows only few series evaluating fertility and obstetric performance after bilateral internal iliac ligation. The data reviewed does not appear to have any adverse effect on menstrual / ovarian function or fertility. We have presented an unusual case of amenorrhea and infertility following bilateral internal iliac ligation done for ruptured uterus and PPH. All parameters of pituitary functions were within normal limits ruling out the possibility of Sheehan's syndrome. New investigational modality using color Doppler has clearly shown absent or diminished uterine artery flow velocimetry.

INTRODUCTION: Internal iliac ligation is a therapeutic option for severe PPH. Little is known about the outcomes of subsequent fertility and pregnancy. There are several case reports but NO large series with follow up. ${ }^{1}$

The collateral system opens up immediately after internal iliac ligation so efficient that even bilateral ligation does not result in tissue necrosis or interferes with subsequent menstrual or reproductive functions. ${ }^{2}$ As with internal iliac ligation, subsequent menstrual and reproductive functions are usually unaffected by angiographic embolization of pelvic vessels, although uterine necrosis can occur on rare occasions. ${ }^{3}$

Here we are presenting a case report of a patient with internal iliac ligation (IIL) coming for infertility and amenorrhea following IIL where all pituitary functions are within normal limits.

CASE REPORT: Age 25 Para 1 death 1 (stillbirth) lady came with the c/o infertility and amenorrhea following internal iliac artery ligation done 8 year ago in a village for uterine rupture and bilateral broad ligament hematomas. Referral notes say (b/l) int iliac artery was ligated and 4 bottles of blood (group B +ve) were given during the procedure.

Patient had a stormy post-operative period and was given blood transfusion/I.V fluids /antibiotics like Gatifloxacin for 10 days. Patient had amenorrhea following this delivery (which was a stillbirth).

Patient was investigated especially with a view to rule out Sheehan's syndrome. However her FSH/LH/TSH/Prolactin/E2/ levels were surprisingly WNL. Also MRI of sella turcica showed normal pituitary.

Sr. FSH $-6.38 \mathrm{mIU} / \mathrm{ml}$

Sr. $\mathrm{LH}-4.50 \mathrm{mIU} / \mathrm{ml}$

Sr. Prolactin - 1.61ng/ml [referral range 1.20 - 19.50]

Sr. TSH - 1.30 [referral range 0.39 - 6.16]

Sr. Estradiol - 59.35 [referral range 19.5 - $144.2 \mathrm{pg} / \mathrm{ml}$ in follicular phase]

Sr. Calcium $-8.5 \mathrm{mg} / \mathrm{dl}$ 
Our patient was given conjugated estrogen tablets $0.625 \mathrm{mg}$ daily for 3 months and a progesterone challenge test (progesterone 10mg twice for 5 days) to achieve a withdrawal bleeding.

Patient neither had a breakthrough bleeding in the 3 months of estrogen treatment nor did she have menstrual bleeding after the progesterone challenge test.

On Per Speculum examination, the cervix was severely atrophied. Could only be identified as a small dot like structure which could not be held even by a volsellum nor could a uterine sound be inserted through the cervix.

Pelvic MRI shows a small uterus measuring 5.5 by $2.6 \mathrm{cms}$, thinning of the junction zone of uterus is noted between fundus and the body of uterus.

The fundal region measures about $2.5 \mathrm{cms}$.

The zone in the body and the cervix appear homogeneously measuring $8 \mathrm{~mm}$, and both ovaries appear normal.

There is evidence of STIR hyperintensity noted involving posterior rim of right acetabulum in subcortical aspects.

Uterine artery color Doppler study showed No flow in (R) uterine artery and diminished flow in (L) uterine artery.

DISCUSSION: Ligation of int iliac artery has proven helpful in the management of PPH. Burchell's 4,5 arteriographic studies has shown that physiologically active anastomoses between systemic and pelvic arterial supplies were immediately established and remains patent after the ligation of internal iliac artery (see fig). Burchell (1960) showed that unilateral ligation reduced the pulse pressure by about $75 \%$ on ipsilateral side and $85 \%$ with B.I.L. This reduced pulse pressure which is equivalent to venous systemic pressure and allows clotting to occur because the "trip hammer" effect is abolished. Blood flow does not stop completely due to collateral anastomoses. This collateral circulation is so efficient that even bilateral ligation does not result in tissue necrosis or interfere with subsequent menstrual or reproductive function ${ }^{1}$

In our case, color Doppler of uterine artery clearly showed no flow in (R) uterine artery and reduced flow in (L) uterine artery. Since all her pituitary functions are within normal limits (which rules out Sheehan's syndrome) clearly points to diminished blood supply to uterus/adnexa. Her ovaries show presence of follicles probably suggestive of normal ovarian blood flow.

Considering the normal ovaries and the severity of thinning and atrophy of the body of the uterus and the cervix, while a normal fundal region as seen in the MRI suggests a normal ovarian blood flow which supplies to the fundal region while an atrophy of the body and cervix which is supplied by the uterine artery. 


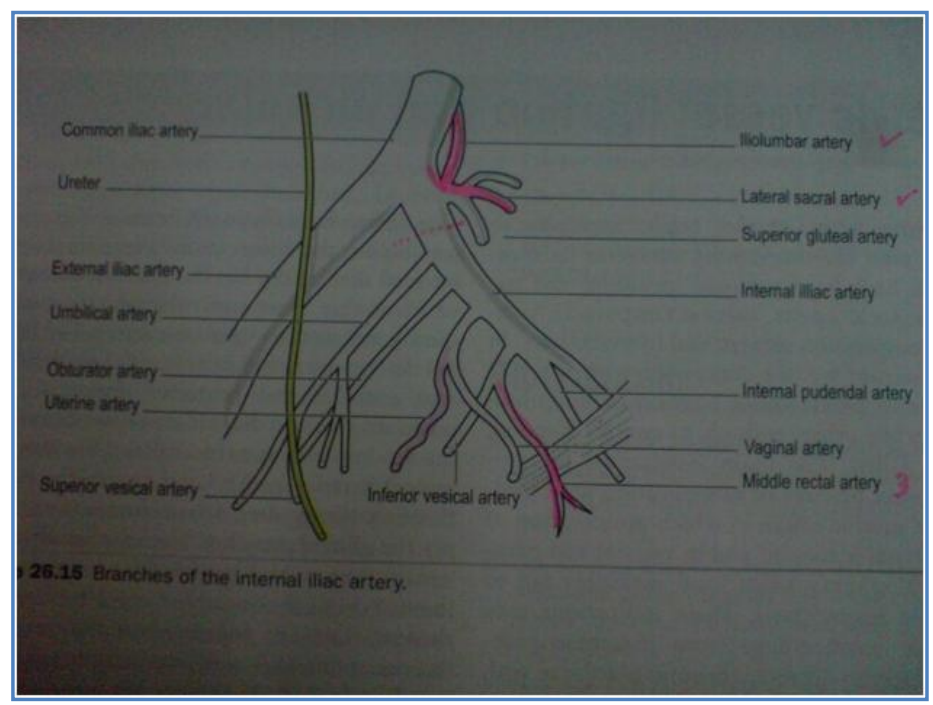

Also there is evidence of STIR hyperintensity noted involving posterior rim of right acetabulum seen on MRI which suggests a degenerative change in the acetabulum. This is probably because the acetabulum is mainly supplied by the branch of the obturator artery which in turn is a branch of the internal iliac artery.

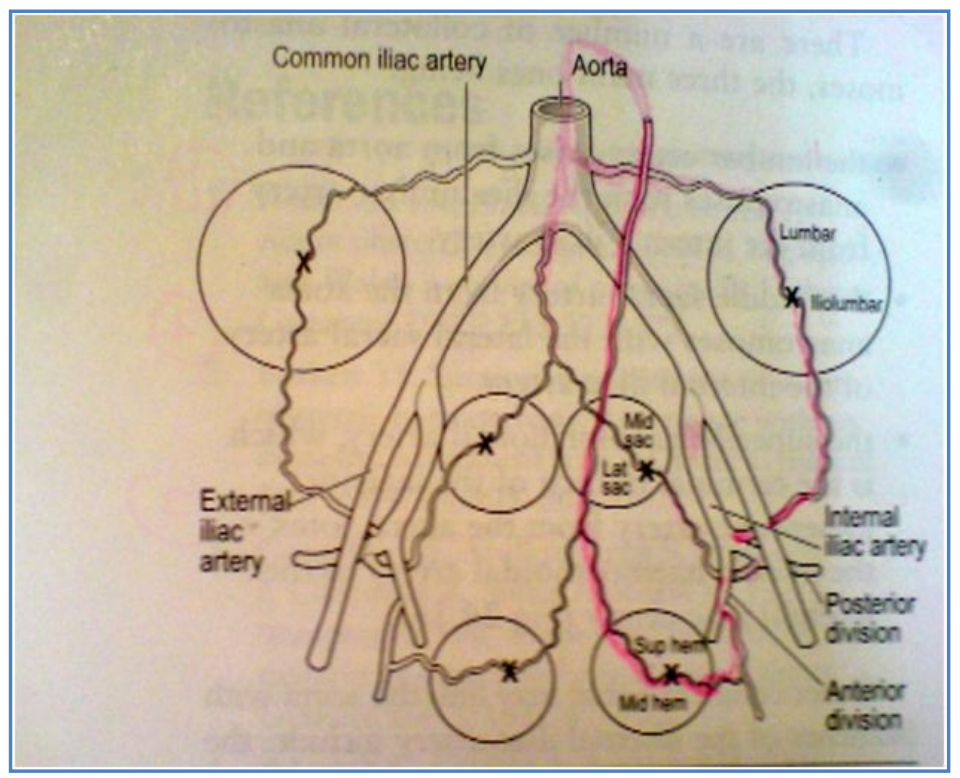

SUMMARY: Here is a case of internal iliac ligation which shows diminished blood flow to uterus causing amenorrhea and infertility and atrophied uterus contrary to many reports which show normal uterine /ovarian function after B.I.L.

\section{REFERENCES:}

1. Joshi V, Otiv S, Majumdar R, Nikam Y, Shrivastava M. Internal Iliac artery ligation for arresting post-partum hemorrhage. DJOG 2007; 114: 356-61.

2. Likeman R.K. The boldest procedure possible for checking the bleeding - a new look at old operation and series of 13 cases from Australian hospital. Aust N Z J. Obs/Gyn 1992. 
3. Cottier JP, Fignon A, Tranquart F, Herbreteau D. Uterine necrosis after arterial embolisation for post partum hemorrhage. Obstet Gynecol 2002; 100: 1074-1077.

4. Burchell R. C. Arterial physiology of human female pelvis. Obst Gyn 1968; 31: 855.

5. Burchell R.C. Physiology of internal iliac artery ligation. J Obstet Gynaecol Br Commonw 1968; 75: 642-651.

6. Latika Sahu, Rani Reddi. Emergency internal iliac ligation- For intractable obstetrics \&gynecological pelvic hemorrhage. International Journal of Gyn \& Obs India (July-August 2011)239-242.

\section{AUTHORS:}

1. Sumit H. Paranjpe

2. PratimaThamke

3. B.G. Boricha

\section{PARTICULARS OF CONTRIBUTORS:}

1. PG Resident, Department of Obstetrics and Gynaecology, M.G.M Hospital and Medical College, Navi, Mumbai.

2. Lecturer, Department of Obstetrics and Gynaecology, M.G.M Hospital and Medical College, Navi, Mumbai.

3. Professor and HOD, Department of Obstetrics and Gynaecology, M.G.M Hospital and Medical College, Navi, Mumbai.

\section{NAME ADDRESS EMAIL ID OF THE CORRESPONDING AUTHOR:}

Dr.Sumit H Paranjpe,

$44 / 101,15^{\text {th }} \mathrm{Rd}$,

Chembur, Mumbai - 400071.

E-mail: malaypratima@yahoo.com

Date of Submission: 30/12/2013.

Date of Peer Review: 31/12/2013.

Date of Acceptance: 14/01/2014.

Date of Publishing: 23/01/2014 